\title{
Polydipsia as a Precursor of Manic Episode in Bipolar Affective Disorder Patients with Alcohol Use Disorder
}

\author{
Mehmet Emin Ceylan ${ }^{1,2}$, Bariş Önen Ünsalver ${ }^{3}$, Alper Evrensel ${ }^{1}$ \\ Departments of ${ }^{1}$ Psychology and ${ }^{2}$ Philosophy, ${ }^{3}$ Department of Medical Documentation and Secreteriat, Vocational School of Health Services, \\ Üsküdar University, Istanbul, Turkey
}

\begin{abstract}
Bipolar affective disorder (BD) diagnosis and initiation of appropriate treatment are often delayed, and this is associated with poorer outcomes, such as rapid cycling or cognitive decline. Therefore, identifying certain warning signs of a probable successive episode during the inter-episode phase is important for early intervention. We present the retrospective data of three cases of BD. Our first case had a history of alcohol use disorder (AUD), where he drank in a dipsomaniac manner, and the other two cases had dipsomaniac alcohol use before their manic attacks, and none of them had any AUD after the mood episode was over. Two brothers also had hypertensive episodes during the manic attacks. None of the cases reported increased fluid intake when they were euthymic. We suggest that polydipsia in BD may be a warning sign of an upcoming manic episode, especially in those patients with AUD. Polydipsia in BD may be caused or facilitated by a combination of hyperdopaminergic activity, hypothalamic dysfunction, and dysregulated renin-angiotensin system. To be able to prevent new episodes, a patient's drinking habits and change in fluid intake should be asked at every visit. Those patients with a history of alcohol abuse should especially be informed about polydipsia and manic episode association.
\end{abstract}

KEY WORDS: Polydipsia; Manic disorder; Binge drinking; Comorbidity; Alcoholism.

\section{INTRODUCTION}

Bipolar affective disorder (BD) causes severe suffering in patients and their relatives and enforces high economic costs on the healthcare system. The total lifetime prevalence estimate for the BD spectrum is $2.4 \%$, ${ }^{1)}$ and it is the sixth leading cause of disability among mental disorders worldwide. ${ }^{2)}$ Regarding the prevalence and public health costs of $\mathrm{BD}$, it is clear that the research for understanding the pathogenesis, course, and treatment of the disease is paramount.

BD often starts with a depressive episode. During the prodrome phase of a first manic episode, patients have symptoms like mood fluctuation, sleep disturbance, and functional impairment, which are non-specific symptoms that might be seen in other psychiatric syndromes as

Received: August 16, 2016/Revised: October 20, 2016 Accepted: November 1, 2016

Address for correspondence: Bariş Önen Ünsalver, MD Department of Medical Documentation and Secreteriat, Vocational School of Health Services, Üsküdar Üniversitesi NP Feneryolu Polikliniği, No:109/A, 34724, Istanbul, Turkey Tel: +90-2164181500, Fax: +90-2164181530

E-mail: onenunsalver@gmail.com well. ${ }^{3)}$ These make it difficult to predict a first hypomanic or manic episode. BD diagnosis and initiation of appropriate treatment are often delayed. ${ }^{4)}$ The delay in diagnosis and treatment of BD is associated with poorer outcomes like rapid cycling or cognitive decline. ${ }^{5)}$ The staging model of BD suggests that the disease progresses from mild to severe presentations in time. Therefore, the early management of BD is critical to prevent further progression. ${ }^{6)}$

In our clinical practice, we have observed some of our patients reporting polydipsia before the onset of a manic episode. Polydipsia is common in schizophrenic patients but is rarely reported in $\mathrm{BD} .^{7,8)}$ We suggest that polydipsia may be one of the early signs of a manic episode, especially in those patients with alcohol use disorders (AUD). We will briefly present three BD cases with polydipsia.

\section{CASE}

\section{Case 1}

A 33-year-old male patient responded to treatment

(c) This is an Open-Access article distributed under the terms of the Creative Commons Attribution Non-Commercial License (http://creativecommons.org/licenses/by-nc/4.0) which permits unrestricted non-commercial use, distribution, and reproduction in any medium, provided the original work is properly cited. 
with amitriptyline $75 \mathrm{mg} /$ day for major depression (MD). He had a previous history of AUD with episodes of dipsomania. By the end of the third month of antidepressant treatment, his daily intake of water had increased from 4 L/day to 14 L/day. His alcohol consumption didn't change. Soon after these complaints of polydipsia, he became more talkative, had a decreased need for sleep, and was overspending money, so diagnosis of a manic episode was made, and he was started on chlorpromazine $100 \mathrm{mg} /$ day, zuclopenthixol $20 \mathrm{mg} /$ day, and biperiden 2 $\mathrm{mg} /$ day. The manic symptoms resolved, and his daily water drinking decreased to $5 \mathrm{~L}$ /day after four weeks of treatment. By the third year of remission, his water drinking again increased from $4 \mathrm{~L} /$ day to $8 \mathrm{~L} /$ day, and a second manic episode ensued.

\section{Case 2}

A 35-year-old male patient who had been on paroxetine $20 \mathrm{mg} /$ day and modafinil $100 \mathrm{mg} /$ day treatment for $\mathrm{MD}$ for the past six months came to the outpatient clinic complaining of feeling thirstier. He drank more water than usual (5 L/day), had cravings for alcohol, and had a blackout during a dipsomaniac alcohol drinking episode. A week later, his energy levels increased and he became distractable and irritable. Therefore, he was diagnosed with a manic episode. Paroxetine and modafinil were stopped, and he was started on valproic acid $750 \mathrm{mg} /$ day and aripiprazole $10 \mathrm{mg} /$ day. His arterial blood pressure measurements were frequently above $140 / 90 \mathrm{mmHg}$; so he was started on amlodipine $5 \mathrm{mg} /$ day. The manic episode resolved in a month, and his thirst decreased. He no longer craved for alcohol. His antihypertensive drug was stopped by the first month because of hypotension. He has been in remission for the past 13 months.

\section{Case 3}

Forty-two year-old male patient is the brother of Case 2 who was followed up by the same physician. He also had a diagnosis of $\mathrm{BD}$ with MD as the first presenting mood episode. According to his medical records during his two manic episodes, he also had complained about increased thirst, dipsomaniac alcohol drinking, and hypertensive attacks that resolved during euthymic states. He has been in remission for the past eight years with chlorpromazine 25 $\mathrm{mg} /$ day and has not been drinking alcohol since because he thinks alcohol triggers the episodes.

\section{DISCUSSION}

We have presented three male cases of BD, whose first episodes were MD, and who had polydipsia before the onset of a manic episode. None of the cases had a history of diabetes mellitus or diabetes insipidus that might have induced polydipsia. Even though the information about the third case is retrospective, it is included to support the genetic background of $\mathrm{BD}$ and to highlight the co-occurrence of hypertensive episodes with the manic attacks. None of the cases reported increased fluid intake during euthymia.

Polydipsia is defined as drinking more fluids than the physiologic needs of the body, which has been suggested to be more than $3 \mathrm{~L} /$ day. ${ }^{9)}$ Clinically, the patient drinks large amounts of fluids and has polyuria. Polydipsia may cause hyponatremia and water intoxication, manifested by psychiatric symptoms, nausea, vomiting, delirium, ataxia, seizures, coma, and even death when untreated. ${ }^{10)}$ Psychogenically induced polydipsia (PPD) is mainly seen in schizophrenia among other psychiatric syndromes ${ }^{7)}$ and may be a coping mechanism in stressful conditions. ${ }^{11)}$ PPD is a multifactorial dysfunction of the hypothalamicpituitary axis (HPA). Chronic consumption of excess fluid might be changing the feedback regulation of HPA. ${ }^{12)}$

Polydipsia in BD may share a common etiologic factor with polydipsia in schizophrenia. As previously suggested, elevated levels of dopamine might be stimulating the thirst center. ${ }^{13)}$ To explain the development of psychogenic polydipsia in schizophrenia, in an animal model, repeated treatment with D2/D3 agonist quinpirole was shown to induce hyperdipsia ${ }^{14)}$ in a compulsive manner. ${ }^{15)}$ Many of the behavioral abnormalities seen in BD may be related to hyperdopaminergic activity, ${ }^{16)}$ especially in the mesolimbic pathway, ${ }^{17)}$ which might constitute the basis for hyperdipsia in BD as well. In agreement with this, all of our patients responded to antipsychotic drugs. Hyperdopaminergic activity is temporary in BD during a manic episode, which supports the idea of polydipsia as an early sign of a manic episode. None of our patients had polydipsia after their manic episodes were over.

Our first case had a history of AUD, when he drank in a dipsomaniac manner, and the other two cases had dipsomaniac alcohol use before their manic attacks; however, none of them had any AUD after the mood episode was over. Alcohol abuse may be another factor contributing to 
polydipsia. Schizophrenic patients with polydipsia have a more frequent history of alcohol abuse. ${ }^{18)}$ Harding et al. ${ }^{19)}$ found that chronic alcoholic men had neuronal loss in vasopressin (VP) producing neurons. Generally, VP release is induced in hyperosmolar plasma states, resulting in decreased urine production and increased thirst; however, chronic alcohol use may disrupt VP release, and osmotically inappropriate thirst responses like polydipsia may ensue. ${ }^{20)}$

The two brothers, without any family history of hypertension, had increased arterial hypertension during the manic attacks that resolved when the episode ended. The increase in arterial blood pressure may be related to a common factor that results in abnormal fluid intake. Longitudinal follow-up of these two patients shows that as long as they remain in the euthymic state, they don't report any increase in arterial blood pressure or fluid intake which might strengthen the suggested tie between BD manic episodes and polydipsia and concurrent hypertension. Angiotensin II (AngII) is dipsogenic. ${ }^{21)}$ The effects of Angll are mediated by AT1R and AT2R receptors. Hyperactivation of these two receptors is implicated in the pathophysiology of mood disorders by their pro-inflammatory effects. ${ }^{22)}$ Angiotensins may also have regulatory effects on dopaminergic activity in the brain $^{23)}$ which might, in part, explain both the manic episode and polydipsia. Angll is also responsible for increased arterial hypertension, so it might be suggested that concurrent hypertension that resolves after a manic episode is over may be caused by the vasoconstrictor effects of Angll. In light of all these, use of AT1R receptor antagonists as previously suggested by de Góis Queiroz et al. ${ }^{22)}$ may be complementary in the management of manic episodes.

As a summary, we have suggested that polydipsia in BD may be a warning sign of an upcoming manic episode especially in those patients with AUD. Polydipsia in BD may be caused or facilitated by a combination of hyperdopaminergic activity, hypothalamic dysfunction, and dysregulated renin-angiotensin system. Interrelations among these three may form the basis or be a consequence of the basic pathophysiology of $\mathrm{BD}$. To be able to prevent new episodes, a patient's drinking habits and change in fluid intake should be asked at every visit. Regarding the hypertensive episodes in our patients, it is clear that arterial blood pressure measurements should be a regular part of every psychiatric evaluation. Those patients with a history of AUD should be informed about polydipsia and manic episode association.

\section{REFERENCES}

1. Merikangas KR, Jin R, He JP, Kessler RC, Lee S, Sampson NA, et al. Prevalence and correlates of bipolar spectrum disorder in the world mental health survey initiative. Arch Gen Psychiatry 2011;68:241-251.

2. Vos T, Flaxman AD, Naghavi M, Lozano R, Michaud C, Ezzati $\mathrm{M}$, et al. Years lived with disability (YLDS) for 1160 sequelae of 289 diseases and injuries 1990-2010: a systematic analysis for the Global Burden of Disease Study 2010. Lancet 2012; 380:2163-2196.

3. Conus P, Ward J, Hallam KT, Lucas N, Macneil C, McGorry $\mathrm{PD}$, et al. The proximal prodrome to first episode mania--a new target for early intervention. Bipolar Disord 2008;10: 555-565.

4. Patel R, Shetty H, Jackson R, Broadbent M, Stewart R, Boydell $\mathrm{J}$, et al. Delays before diagnosis and initiation of treatment in patients presenting to mental health services with bipolar disorder. PLoS One 2015;10:e0126530.

5. Kessing LV, Hansen MG, Andersen PK, Angst J. The predictive effect of episodes on the risk of recurrence in depressive and bipolar disorders - a life-long perspective. Acta Psychiatr Scand 2004; 109:339-344.

6. Muneer A. Staging models in bipolar disorder: a systematic review of the literature. Clin Psychopharmacol Neurosci 2016;14:117-130

7. Dundas B, Harris M, Narasimhan M. Psychogenic polydipsia review: etiology, differential, and treatment. Curr Psychiatry Rep 2007:9:236-241.

8. Altındağ A, Yanık M, Nebioğlu M. Psychogenic polydipsia in bipolar disorder: a case report. Bull Clin Psychopharmacol 2004; 14:79-82.

9. Koczapski AB, Ibraheem S, Ashby YT, Paredes J, Jones BD, Ancill R. Early diagnosis of water intoxication by monitoring diurnal variations in body weight. Am J Psychiatry 1987; 144:1626-1627.

10. Hawken ER, Crookall JM, Reddick D, Millson RC, Milev R, Delva N. Mortality over a 20-year period in patients with primary polydipsia associated with schizophrenia: a retrospective study. Schizophr Res 2009;107:128-133.

11. Özgün F, Ertemir M, Ceylan ME, Demir C. Stress and polydipsia. Bull Clin Psychopharmacol 2002;12:86-88.

12. Kohli A, Verma S Jr, Sharma A Jr. Psychogenic polydipsia. Indian J Psychiatry 2011,53:166-167.

13. Illowsky BP, Kirch DG. New information on polydipsia and hyponatremia in psychiatric patients. Am / Psychiatry 1988; 145:1039

14. Amato D, Müller CP, Badiani A. Increased drinking after intra-striatal injection of the dopamine D2/D3 receptor agonist quinpirole in the rat. Psychopharmacology (Berl) 2012;223. 
457-463.

15. Schepisi C, Cianci S, Bedse G, Fu J, Gaetani S, Nencini P. Differences in the structure of drinking, cart expression and dopamine turnover between polydipsic and non polydipsic rats in the quinpirole model of psychotic polydipsia. Psychopharmacology (Berl) 2014;231:3889-3897.

16. Anand A, Barkay G, Dzemidzic M, Albrecht D, Karne H, Zheng $\mathrm{QH}$, et al. Striatal dopamine transporter availability in unmedicated bipolar disorder. Bipolar Disord 2011;13: 406-413.

17. Cousins DA, Butts K, Young AH. The role of dopamine in bipolar disorder. Bipolar Disord 2009; 11:787-806.

18. Poirier S, Legris G, Tremblay P, Michea R, Viau-Guay L, Mérette C, et al. Schizophrenia patients with polydipsia and water intoxication are characterized by greater severity of psychotic illness and a more frequent history of alcohol abuse.
Schizophr Res 2010;118:285-291.

19. Harding AJ, Halliday GM, Ng JL, Harper CG, Kril JJ. Loss of vasopressin-immunoreactive neurons in alcoholics is dose-related and time-dependent. Neuroscience 1996;72:699-708.

20. Zerbe RL, Robertson GL. Osmoregulation of thirst and vasopressin secretion in human subjects: effect of various solutes. Am J Physiol 1983;244:E607-E614.

21. McKinley MJ, Johnson AK. The physiological regulation of thirst and fluid intake. News Physiol Sci 2004;19:1-6.

22. de Góis Queiroz Al, Medeiros CD, Ribeiro BM, de Lucena DF, Macêdo DS. Angiotensin receptor blockers for bipolar disorder. Med Hypotheses 2013;80:259-263.

23. Carlsson A, Waters N, Holm-Waters S, Tedroff J, Nilsson M, Carlsson ML. Interactions between monoamines, g/utamate, and GABA in schizophrenia: new evidence. Annu Rev Pharmacol Toxicol 2001;41:237-260. 